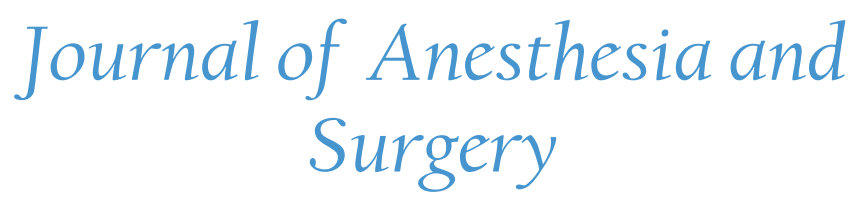

\title{
"Fast-Track" Protocol for Penile Curvature Treatment
}

\author{
Víctor Navalón-Monllor², Alba Monzó-Cataluña1, Celia Ramada-Calaforra², Felipe Ordoño-Domín- \\ guez $^{2}$, Yoni Pallas-Costa ${ }^{1}$, Pedro Navalón-Verdejo ${ }^{1,2^{*}}$
}

${ }^{1}$ Urology Department, General University Hospital of Valencia,Valencia, Spain

${ }^{2}$ Urology Department, University Hospital “Casa de Salud”, Catholic University San Vicente Mártir,Valencia, Spain

"Corresponding author: Pedro Navalón Verdejo, Paseo Alameda 38- 2, 46023, Valencia, Email: pedronavalon@yahoo.com

\begin{abstract}
Objectives: To describe a multimodal recovery protocol (fast-track surgery) for surgical treatment of penile curvature, as developed by the urology department at the General University Hospital of Valencia over the course of the last 10 years. Our aim was to demonstrate that the use of this protocol improves cost-effectiveness of the procedure, when compared to the classical procedure which requires hospital admission and general or spinal anesthesia.

Material and Methods: We compared two groups of patients. The first group underwent strict ambulatory corporoplasty under our multimodal recovery protocol in an out-patient setting, with data collected prospectively. The second group of patients underwent curved penis surgery following the classical procedure before the multimodal recovery protocol was implemented, data was collected retrospectively. We evaluated the inclusion criteria and hospital discharge, as well as obtained results and degree of satisfaction through elaboration of a questionnaire.

Results: Results obtained with fast-track protocol were comparable to those of conventional surgery, providing a null incidence of complications except for the inevitable shortening of the penis, clearly independent of the outpatient procedure regimen. The satisfaction degree with the received treatment was found to be over $95 \%$.

Conclusions: Virtually all patients affected by penile curvature could are suitable candidates for a fast-track surgery program, with the consequent improvement in cost-effectiveness of the procedure and no reduction of the quality of care received or patient satisfaction.
\end{abstract}

Received date: May 20, 2017

Accepted date: July 18, 2017

Published date: July 22, 2017

Citation: Navalón, P., et al. "Fast-Track" Protocol for Penile Curvature Treatment. (2017) J Anesth Surg 4(2): 71- 76.

DOI: $10.15436 / 2377-1364.17 .076$

Keywords: Fast-track; Multimodal rehabilitation; Ambulatory Surgery; Penile curvature

\section{Introduction}

Although fast-track surgery was initially described in colorectal disease, good outcomes obtained with this approach have resulted in its practice by other specialties, such as anesthesia, thoracic surgery, gynecology and urology, among others, where this concept has shown improvement in postoperative recovery $^{[1-5]}$. Using protocols which advocate for a multimodal approach, combining postoperative procedures based on scientific evidence, reduces surgical stress and improves postoperative recovery ${ }^{[6,7]}$.

Moreover, the growing interest in both, improving the cost-effectiveness of hospital processes and producing a lower social and labor disruption in patients, has favored the unstoppable advance of Major Outpatient Surgery (MOS). One of the methods used to achieve these short-term stays in hospitals, is precisely this new concept of "fast-track surgery", as an expression of a coordinated effort that combines modern concepts of patient education with new schemes of analgesics, anesthetics and minimally invasive surgical techniques ${ }^{[8-13]}$.

The most effective treatment for penile curvatures is the Nesbit surgical procedure ${ }^{[14]}$, including the multiple plication variants described afterwards ${ }^{[15,16]}$. It is the most widely used technique for treating this entity. The original technique of Nesbit currently constitutes the "Gold standard "with which all other techniques are compared. It also satisfies all the necessary criteria to be considered a surgical procedure capable of being included in a MOS program, as it is usually young, sexually active patients, in whom the surgical-anesthetic risk is low or null. The technique also meets all inclusion criteria recommended by the Spanish MOS guidelines ${ }^{[17]}$. 


\section{Patients and Methods}

In January 2000, the urology department of the General University Hospital, became part of the MOS unit. Since then, after approval of the institution's ethic board, 300 patients have undergone curved penis treatment in a strict outpatient surgery setting. However, it was not until mid-2007 when a protocol following the fast-track surgery concept for curved penis intervention was designed. This protocol has been periodically updated guided by outcomes assessment, being the last update in January 2012.

To perform this study, we compared two groups of patients. The first group was comprised by patients who underwent curved penis surgery following the multimodal recovery protocol (fast-track group), data was collected prospectively. The second group encompassed patients who underwent curved penis surgery before the multimodal recovery protocol was designed (classical group). Patients included in the classical group were treated under the classical concepts of hospitalization and surgery with general or spinal anesthesia. In this group, data were collected retrospectively.

The inclusion criteria established that all patients accepted the surgical intervention, presented an acceptable surgical-anesthetic risk and had been diagnosed of penile curvature (congenital or acquired) through detailed anamnesis, clinical examination and autophotography. We did not include in the study patients who had congenital curved penis with concomitant hypospadias, since in these cases, the type of intervention as well as the anesthetic technique differ greatly from the technique used in this report.

From January 2012 to January 2017, we have surgically intervened 56 patients (fast-track group), affected by penile curvature, 34 patients with congenital curved penis without hypospadias, and 22 patients with Peyronie's disease. The original Nesbit cavernoscopy technique, on an outpatient basis following the updated version of the protocol was used. The mean age was 32.2 years (range 14 - 66).

The indication to intervene was motivated by the penis incurvation in 32 cases $(57 \%)$, the difficulty of penetration in $16(29 \%)$ and in 8 cases $(14 \%)$, the impossibility of penetration. In order to objectivise the degree and type of curvature, the self-photographed erection method proposed by Kelami ${ }^{[18]}$ was used.

Regarding physical status of patients, we followed the surgical-anesthetic risk criteria endorsed by the American Society of Anesthesiologists (ASA).38 patients ASA I (68\%), 15 patients ASA II (27\%), and 3 stable patients ASA III (5\%) were included in the fast track group.

According to the protocol, a detailed history taking and complete physical examination were performed during the first medical visit. Degree of curvature was evaluated with the self-photograph y provided by the patient. Pre-anesthetic assessment was requested and information about the procedure was given. The informed consent was signed in all cases. In addition, a brochure explaining the process was given to the patients (Figures $1 \mathrm{~A}$ and $1 \mathrm{~B}$ ) which included all preoperative and postoperative instructions as well as a telephone number for assistance if any complications arose.

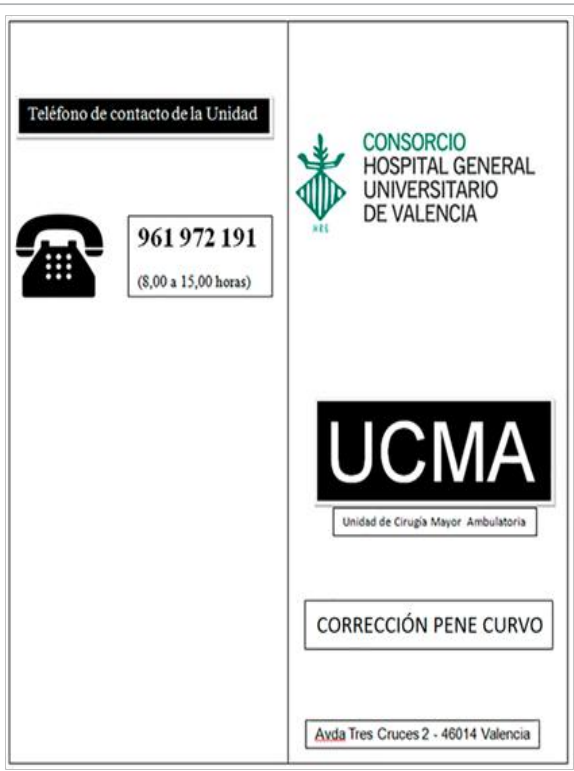

Figure 1A: Explanatory brochure (back cover).

\begin{tabular}{|l|l|}
\hline PREOPERATIVE & POSTOPERATIVE \\
RECOMMENDATIONS & RECOMMENDATIONS \\
\hline
\end{tabular}

1. You will be notified about the 1 . You must rest at home during date you have to go for hospital the first four days after the surgery admission

2. Eat a light dinner the night before surgical procedure. Then you have to fast.

2. Eat a soft meal during the first 24 hours after the surgery. Do not drive. Do not drink alcoholic beverages

3. The day of the procedure do 3. You may have pain in the surnot eat or drink anything (except gical site. Take the analgesic preif you were prescribed with some scribed during the first 48 hours medication)

4. To minimize the risk of wound 4. You may have a little rise in infection, shave your pubis area body temperature $\left(100,4^{\circ} \mathrm{F}\right)$. It and base of the penis and take a is normal during the first 48-72 shower the morning of surgical hours. If you have a higher body intervention temperature, let us know

5. If you use dental prostheses 5. Try to avoid erections, being or intraocular lenses, take them great for this the application of off before coming to the hospi- local cold

tal. Wear comfortable clothes and tight underpants

6. Take your usual medications

6. The day after the procedure, come to meet us at the time scheduled to remove the catheter and compression bandage

7. If you have had any changes in 7 . You do not have to remove the your health, let us know (fever, common cold, etc.)

suture. It is an absorbable suture. Stiches fall usually in a week, but they can fall even later (until 1 month)

8. Come to the hospital with a re- 8 . Ensure proper hygiene of the sponsible adult. You cannot drive wound by washing daily with cars either before or after the pro- soap and water cedure

9. Avoid sexual activity during the first $40-45$ postoperative days

10. If you have any situation (i.e. bleeding) go to the emergency department or call us (609 360315$)$

Figure 1B: Explanatory brochure (frontcover). 
Once the pre-anesthetic assessment was completed without incidences, time and date for hospital admission was notified to the patients. Surgical correction of penile curvature was performed in all patients following the subsequent surgical sequence; $50 \%$ lidocaine and prilocaine cream (EMLA ${ }^{\circledR}$ cream) were applied at home, spread topically over the entire surface of the penis approximately one hour before surgery. Intra-trilateral infiltration at the base of the penis with local anesthetic (lidocaine $2 \%$ ), making an additional infiltration in the dorsal side, directed towards the suspensory ligament of the penis, where the dorsal vasculature-nerve pack runs. Circumferential coronal incision associated with postectomy in case of redundant foreskin. Exposure of Buck's fascia after blunt dissection of the skin as far as the base of the penis. Intraurethral instillation of local anesthetic xylocaine gel. Assessment of the degree and direction of curvature by artificial erection, induced by intracavernous injection of saline serum prior to placement of a compressive band on the root of the penis. Longitudinal incision at lateral level of Buck's fascia reaching the tunica albuginea. Excision of one or several ellipsoidal fragments of the tunica albuginea in the convexity of the curvature and subsequent continuous suture of the defect using polyglycolic acid 3/0 (Dexon ${ }^{\circledR}$ ), avoiding causing any injuries to the vascular and nervous package in the ventral curvatures nor the urethra in the dorsal. Verification of the degree of rectification by means of a second artificial erection, repeating the process if necessary until an acceptable correction is achieved, the patient can also participate in the acceptance of the straightening degree. Closing of Buck's fascia using polyglactin 4/0 (Vicryl rapid $\left.^{\circledR}\right)$. Suture of circumcision with polyglactin 4/0. Urethrovesical probing with Foley $18 \mathrm{Ch}$ probe and compression bandage, which will be removed at 24 hours.

In all cases, antibiotic prophylaxis was performed. A single antibiotic dose (usually cephalosporin: Cefuroxime 750 mg intravenously) was administered prior to the surgical procedure. Postoperative recommendation was given, describing the administration of minor analgesics (oral metamizole magnesium up to 2 g every 6 hours) and diazepam, as well as extreme hygiene measures of the surgical wound. Patients were also advised to abstain from sexual activities for a period of 6 to 8 weeks post intervention.

After surgery, all patients remained under observation for 1 hour until discharge in the post-anesthetic recovery unit of the MOS. Patients and their relatives were provided with an epicritic report detailing the care to be performed at home. It included information on wound care, recommended hygiene, and diet to be followed during the first hours and the following days; recommended mobilization and date of the next appointment as well as a 24-hour hospital assistance telephone number.

Patients receive a post-operative phone call by the medical or nursing staff of the MOS unit on the evening of the intervention and the next morning, to control their postoperative conditions and avoid the in attentive feelings that could result from outpatient surgery. If necessary, the patient is referred to the emergency department of the hospital. The next morning, patients check in at the MOS unit where the catheter and the compression bandage are removed. The postoperative medical visits are performed a week, one month and three months after surgical procedure. At medical office, we performed a short anonymous survey concerning satisfaction degree on the received treatment. The mean post-operative follow-up was of 21 months (range $3-60$ ).
In order to compare results with a control group of patients operated classically by inpatient surgery with spinal or general anesthesia (classic group), we studied retrospectively patients who had under gone curved penis surgery during the 2 years prior to the establishment of the fast-track protocol. From January 2005 to January 2007, 21 patients aged between 18 and 72 years (mean, 34.1) underwent Nesbit corporaplasty. 12 patients had congenital curved penis and the 9 remaining patients had Peyronie's disease.

Regarding the physical state, 15 patients were qualified as ASA I (71\%), 5 ASA II (24\%), and 1 ASA III well compensated (5\%). In the classical group, 14 patients (67\%) underwent surgery under spinal anesthesia and 7 patients (33\%) under general anesthesia. All patients were admitted at the hospital. Regarding the statistical analysis of results, data are expressed with the mean, standard deviation and range. The analysis was performed using SPSS 19 statistical package (SPSS Inc., Chicago, IL). When necessary to compare groups, the Student-t test was used, considering statistical significance at $p<0.05$. When we compared qualitative aspects, the chi-square test was used.

\section{Results}

There were no statistically significant differences between both groups on age, anesthetic-surgical risk, laterality of the injury or etiology of penile curvature, therefore both groups comprising the study were homogeneous. All patients in the fast-track group had under gone surgery with local anesthesia, requiring between 8 and $10 \mathrm{ml} \%$ lidocaine. In 5 cases (9\%) it was necessary to add sedo-analgesics through infusion of propofol and remifentanil due mostly to the severe anxiety symptoms in some patients instead of pain or intolerance to the procedure. The average time used for the surgical intervention in the fasttrack group was $50 \pm 10$ minutes (range $35-70)$. In the classic group, the time was significantly greater $(p<0.0005)$, being the average $85 \pm 15$ minutes (range 50 - 105).

All patients from the fast-track group were discharged after intervention, with none of them requiring hospital admission as a result of immediate intra or postoperative complications. A total of 4 patients $(7 \%)$ were attended in the emergency department during the first postoperative day, all of them due to intolerance to the catheter, which was resolved by increasing the analgesic and anxiolytic regimen.

Patients from the classic group, stayed in hospital, being the mean length of stay of $1.8 \pm 0.8$ days (range $1-5$ ) with no significant complications.

\section{Discussion}

The Nesbit procedure consists basically in the excision of one or several ellipsoidal fragments of the tunica albuginea at the contralateral point to the curvature and its posterior suture. This technique has been widely used by numerous authors with excellent results in congenital penile incurvations. Results are somewhat worse, in patients with Peyronie's disease, mainly due to the shortening resulting from this technique in a patient whose penis is already shortened by the disease itself. However, in face of the effectiveness of patch or prosthesis implantation techniques for curved penis correction in selected cases ${ }^{[20-23]}$, we oppose the results of our experience through the Nesbit corpora- 
plasty, carried out under local anesthesia following the protocol of fast-track surgery, which we believe is a reproducible technique regardless of population type, which does not require an exhaustive selection of patients in terms of their physical state. This technique allows for improvement of health resources performance and in turn, reduces the derived morbidity of the surgical and anesthetic act.

We prefer lidocaine as a local anesthetic instead of other amide compounds (mepivacaine, bupivacaine and ropivacaine), due to its lower cardiotoxic effect (if it were accidentally injected into the bloodstream), its faster anesthetic action and its less painful sensation during infiltration. We also prefer its use because it is the same compound that possesses the xylocaine gel that we use as lubricant to anesthetize the urethra prior to the catheterization.

On the other hand, we believe that a very important advantage of using local anesthesia for these types of interventions is that the patient, being aware, can participate in the degree of rectification and shortening that is obtained from the penis during the intervention, the more dried tissue to straighten the curvature, the shorter the length of the penis. Consequently, a consensus can be reached between doctor and patient. It is also due to the use of local anesthesia instead of general or spinal anesthesia, which is the fundamental cause of the lengthier use of the operating room in the classic group ( $85 \pm 25$ minutes $)$ compared to the fast-track group ( $50 \pm 10$ minutes). Contributing as well to the greater economic savings accomplished in the latter.

There is controversy regarding the type of suture material (absorbable or not) to be used in reparation of the tunica albuginea, since absorbable sutures can cause reinfolding in case of simple plication without creation of bloody area. Moreover, in addition to the inevitable shortening of the penis, the most frequent complication of plication without excision of the tunica albuginea is that it can produce bumps, like "dried apricots", at the level of the plicated area. Likewise, non-absorbable stitches, despite being invaginatingly knotted, may cause discomfort during erection or intercourse, and may even cause an aesthetic problem as they transpire through the skin. Thus, in our opinion, the excision of the albuginea and suture with slow reabsorption material provides excellent results by avoiding the disadvantages that the protrusion of the knots can provoke and that sometimes need to be removed when non-absorbable material is used ${ }^{[24]}$.

Regarding the discussion about using postoperative urethra-vesical catheter or not, although we believe that its systematic use is unnecessary, we consider that in MOS, all available measures should be taken to minimize the risks of complications. However, since the catheter is the worst tolerated part of the immediate postoperative period, lately we only indicate it in those cases that have required several incisions in the cavernous body, or in patients with hemorrhage risk.

On the other hand, it is clear that during the last years, the MOS is advancing in an unstoppable way; In fact, in the United States, where the health care system is the most developed, the MOS accounts for about $60 \%$ of all performed interventions ${ }^{[25]}$. Likewise, the published work in our country's urological journals about this surgical assistance organization system $^{[26]}$ is increasingly frequent, which shows that urology is a specialty with great projection in the MOS field ${ }^{[27]}$.

In addition, it is a fact that once an outpatient procedure is established by a hospital, the number of patients involved in this procedure increases with respect to the traditional one. Indeed, in our experience, we observed that after establishing the fast-track protocol for correction of the curved penis, it gradually replaced the classical surgery that included hospitalization. Thus, as shown in Figure 2, after the first year of implementing the penis curved fast-track protocol, the outpatient setting surgery rate was $35 \%$, reaching at present almost $100 \%$. This instance has been the main limitation of this study, the patient groups we compared could not be studied synchronically; patients from the classical group were intervened between 2005 and 2007. Since instauration of the fast-track protocol some of its concepts were introduced on the classical surgery as consequence of the high acceptance rate by the sanitary personal.

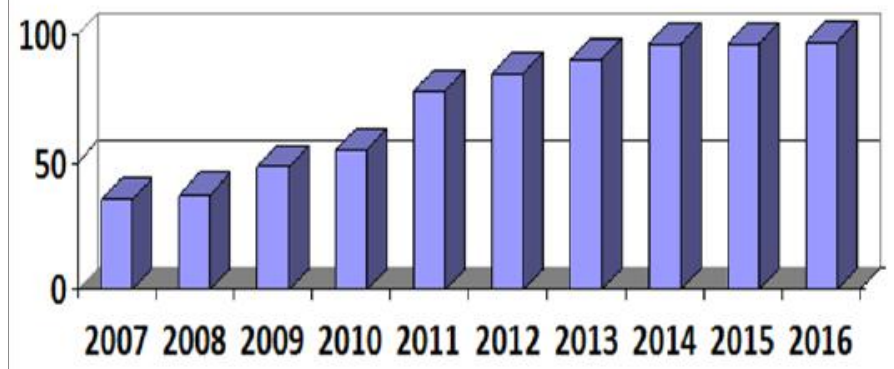

Figure 2: Index of replacement of classic corporoplasty by fast-track.

We agree with the idea proposed by Llopis et $\mathrm{al}^{[28]}$ in which the MOS constitutes a care system that whithers the benefit of all participants. In fact, it benefits the hospital since its use implies a reduction in healthcare cost, which varies between 25 and $75 \%$ according to different authors ${ }^{[29-31]}$. Although the cost of the intervention with outpatient treatment is similar to the process with hospital admission, savings are mainly in hospitality sector and health personnel. In addition, the hospital also benefits from an increase in the number of available beds, since, according to our own experience and that of other authors reviewed, the average hospital stay of patients operated by Nesbit technique with hospital admission varies between 1 and 3 days $^{[19-32]}$.

As far as the patient is concerned, his lifestyle is minimally altered, since he returns home within a few hours of being intervened, significantly reducing his degree of anxiety as well as the probability of hospitalization complications such as nosocomial infections and complications secondary to bedding ${ }^{[33]}$. In addition, their degree of satisfaction is usually high, as our survey shows it is around $95 \%$.

Similarly, we believe that the surgeon benefits as well, since although the MOS can initially be considered a second line surgery, the urologist soon becomes involved in a work system where "anything goes" to minimize risks. Application of lidocaine and prilocaine gel one hour before the intervention to anesthetize the skin, methodical infiltration with local anesthetic, use of fair incisions, rigorous hemostasis, as well as avoiding unnecessary surgical gestures to shorten the operative time, etc., Represent a professional challenge, which has been enriching and rewarding, at least for our department. Likewise, it supposes a greater professional motivation at the same time as a greater satisfaction index in view of the obtained results. We have had zero incidence of complications, except for the inevitable shortening 
of the penis (usually lacking clinical and legal significance, if extensive information is previously provided and consent is signed), clearly independent of the outpatient or non-outpatient regimen. All of this, implies that currently in our hospital, practically all penile incurvation corrections are performed without the need for admission when following the fast-track protocol. Thus, as we gain more experience, we can expand our procedures portfolio, including pathologies of greater complexity being less and less selective in terms of surgical risk.

We believe the protocol described in this article is easily reproducible in any urology service, it does not require a complex infrastructure and it ostensibly improves cost-effectivity of corporoplasties.

\section{Conclusions}

1. Implementation of fast-track protocols in patients submitted to curved penile corporaplasty, both congenital and acquired, leads to a reduction of length of hospital stay and a decline inpostoperative morbidity, improving the cost-effectiveness of the procedure.

2. Practically all of penile curvature can be solved under local anesthesia in a strict outpatient setting.

3. Corporoplasties performed under spinal or general anesthesia with hospital admission are an unnecessary overuse of health care resources and should be avoided.

Conflict of Interest: Authors declare no conflicts of interest.

\section{References}

1. Fearon, K.H., Ljungqvist, O., Von Meyenfeldt, M., et al. Enhanced recovery after surgery: a consensus review of clinical care for patients undergoing colonic resection. ClinNutr 24: 466-477.

Pubmed | Crossref | Others

2. Pędziwiatr, M., Matłok, M., Kisialeuski, M., et al. Enhanced recovery (ERAS) protocol in patients undergoing laparoscopic total gastrectomy. (2014) Videosurgery Miniinv 9(2): 252-257.

Pubmed | Crossref | Others

3. Taupyk, Y., Cao, X., Zhao, Y., et al. Fast-track laparoscopic surgery: A better option for treating colorectal cancer than conventional laparoscopic surgery. (2015) OncLet 10: 443-448.

Pubmed | Crossref | Others

4. Ortega, S.M., Martínez, J., Júdez, D., et al. Implantación de un protocolo fast-track en cistectomía radical en un hospital terciario. (2015) Actas Urol Esp 39(10): 620-627.

Pubmed $\mid$ Crossref $\mid$ Others

5. Navalón, V., Sobrón, M., Ordoño, F., et al. Development of a "FastTrack" Protocol for Hydrocele Surgery. (2016) J AnesthSurg 3(6): 1- 5. Pubmed | Crossref | Others

6. Moreno, P. Cirugía endocrina en régimen ambulatorio. (2006) Cir Esp 80(5): 273-274.

Pubmed $\mid$ Crossref $\mid$ Others

7. Ortega, J., Cassinelloa, N., Lledó, S. Cirugía tiroidea con menos de 24 horas de hospitalización. Resultados tras 805 tiroidectomías consecutivas en un programa de alta precoz tipo fast-track. (2007) Cir Esp 82(2): 112-116.

Pubmed $\mid$ Crossref $\mid$ Others

8. Ministerio de Sanidad y Consumo. Dirección General de Aseguramiento y Planificación Sanitaria. Cirugía Mayor Ambulatoria: Guía de Organización y Funcionamiento. (1993) Madrid.

Pubmed $\mid$ Crossref $\mid$ Others

9. Jarrett, P., De Lathouwer, C., Ogg, T.W. The time has come to promote true daysurgery. (2000) Amb Surg 8(4): 163-164.

Pubmed $\mid$ Crossref $\mid$ Others

10. De Lathauwer, C., Poullier, J.P. How much ambulatory surgery in the world in 1966 - 1977 and trends. Amb (2000) Surg 8:191-193.

Pubmed | Crossref | Others

11. Rodríguez, J.M., Rodríguez, R., Blanco, G. Cirugía Mayor Ambulatoria en Urología. En: Porrero JL. Cirugía Mayor Ambulatoria $2^{\mathrm{a}} \mathrm{Ed}$. (2002) Barcelona: Masson 311-333.

Pubmed $\mid$ Crossref $\mid$ Others

12. Navalón, P., Zaragoza, C., Cánovas, J.A., et al. Cirugía Mayor Ambulatoria en Urología. Análisis de nuestra experiencia. (2004) Arch Esp Urol 57(5): 513-514.

Pubmed | Crossref $\mid$ Others

13. Navalón, P., Zaragoza, C., Sánchez, F., et al. Corrección del pene curvo en cirugía mayor ambulatoria. (2005) ActasUrolEsp 29(2): 217 -222 .

Pubmed | Crossref | Others

14. Nesbit, R.M. Congenital curvature of the phallus: report of 3 cases with description of corrective operation. (1965) J Urol 93: 230-325.

Pubmed | Crossref | Others

15. Essed, E., Schoroeder, F.H. New surgical treatment for Peyronie's disease. (1985) Urology 25: 282-288.

Pubmed | Crossref $\mid$ Others

16. Erpenbach, K., Rothe, H., Derschum, W. The penile plication procedure. An alternative method for straightening penile deviation. (1991) J Urol 146(5): 1276-1278.

Pubmed | Crossref | Others

17. Ministerio de Sanidad y Consumo. Dirección General de Aseguramiento y Planificación Sanitaria. Cirugía Mayor Ambulatoria: Guía de Organización y Funcionamiento. (1993) Madrid.

Pubmed | Crossref $\mid$ Others 
18. Kelami, A. Autophotography in evaluation of functional penile disorders. (1983) Urology 21: 628-629.

Pubmed | Crossref | Others

19. Benejam, J., Rodriguez Vela, L., Gonzalvo, A., et al. Tratamiento con plicatura modificada de la túnica albugínea en pacientes con incurvaciónpeneana congénita. (1999) Actas Urol Esp 23: 36-42.

Pubmed $\mid$ Crossref $\mid$ Others

20. Fabiani, A., Servi, L., Fioretti, F., et al. Buccal mucosa is a promising graft in Peyronie's disease surgery. Our experience and a brief literature review on autologous grafting materials. (2016) Arch Ital Urol Androl 88(2): 115-121.

Pubmed | Crossref | Others

21. Silva, A., Santillán, D., Chávez, D., et al. Satisfacción de los pacientes con enfermedad de La Peyronie tras cirugía de placa e injerto de pericardio bovino. (2017) ActasUrol Esp 41(2): 103-108.

Pubmed | Crossref | Others

22. Hatzimouratidis, K., Eardley, I., Giuliano, F., et al. EAU Guidelines on penile curvature. (2012) Urology 62: 543-552.

Pubmed | Crossref | Others

23. Montorsi, F., Salonia, A., Briganti, A. Five year follow-up of plaque incision and vein grafting for Peyronie's disease. (2004) J Urol 171: 331-335.

Pubmed $\mid$ Crossref $\mid$ Others

24. RodriguezVela, L., Chantada, V., Fiter, L., et al: Incurvación congénita del pene. En: Martín Morales A, Chantada V, Fiter L y cols. Enfermedad de La Peyronie y otras alteraciones morfométricas del pene Ed Ene SA. (2001) Madrid 101-119.

Pubmed | Crossref | Others
25. Rodríguez, J.M., Rodríguez, R., Blanco, G. Cirugía Mayor Ambulatoria en Urología. En: Porrero JL. Cirugía Mayor Ambulatoria $2^{\mathrm{a}} \mathrm{Ed}$. (2002) Barcelona: Masson 311-333.

Pubmed $\mid$ Crossref $\mid$ Others

26. Elizande, A., Regojo, O., Navarro, J., et al. Urología en un programa de Cirugía Mayor Ambulatoria. (2004) Actas Urol Esp 28(5): 144-147. Pubmed $\mid$ Crossref $\mid$ Others

27. Navalón, P. Urología: una especialidad con gran proyección en cirugía mayor ambulatoria. Sociedad Iberoamericana de Información Científica (edición online). Febrero-2005 (6 pantallas). Disponible en Pubmed $\mid$ Crossref $\mid$ Others

28. Llopis, B., Navarro, J.A., Mola, M.J. Cirugía mayor ambulatoria en urología: 5 años de experiencia. (2003) Actas Urol Esp 27(2): 117-119. Pubmed | Crossref $\mid$ Others

29. Caldamone, A., Rabinowitz, R. Outpatient orchiopexy. (1990) J Urol 127(2): 286-288.

Pubmed | Crossref | Others

30. Sadler, G., Richards, H., Watkins, G. Day-case paediatric surgery: the only choice. (1992) Ann R Coll Surg Engl 74(2): 130-133.

Pubmed | Crossref $\mid$ Others

31. Vargas, C., Rius, G. Cirugía urológica sin ingreso. (1993) Actas Urol Esp 17(2): 87-88.

Pubmed | Crossref $\mid$ Others

32. Rodriguez, J., Franco, E., Prats, J.M. Tratamiento quirúrgico de la incurvación congénita del pene mediante técnica de Nesbit. (2004) Arch Esp Urol 57: 141-145.

Pubmed $\mid$ Crossref $\mid$ Others

33. Sampietro, A., Vaquerizo, A., Fernández, A. Cirugía mayor ambulatoria en Urología: nuestra experiencia. (1995) Arch Esp Urol 48(4): 343-344.

Pubmed $\mid$ Crossref $\mid$ Others
Ommega Online Publishers

Journal Title: Journal of Anesthesia and Surgery (JAS)

Journal Short Name: J Anesth Surg
Journal ISSN: 2377-1364

E-mail: anestheisa@ommegaonline.com

Website: www.ommegaonline.org 